\title{
PReS-FINAL-2130-A: Effectiveness of intravenous cyclophosphamide in severe or refractory juvenile dermatomyositis - a national cohort study UK and Ireland
}

\author{
E Moraitis $^{1 *}$, K Arnold $^{2}$, LR Wedderburn ${ }^{1,2}$, CA Pilkington ${ }^{1,2}$, JDRG \\ From 20th Pediatric Rheumatology European Society (PReS) Congress \\ Ljubljana, Slovenia. 25-29 September 2013
}

\section{Introduction}

Evidence suggests that early and aggressive treatment in Juvenile Dermatomyositis (JDM) improves outcome and prevents complications. Cyclophosphamide has been used as a second-line agent in the treatment of severe or refractory JDM. Published data on the effectiveness of cyclophosphamide in JDM are limited to a previous small case series and case reports.

\section{Objectives}

To describe the response to, and evaluate the effectiveness of, intravenous cyclophosphamide in the patients with JDM from the UK JDM National (UK and Ireland) Cohort and Biomarker Study and Repository for Idiopathic Inflammatory Myopathies.

\section{Methods}

The JDM National (UK and Ireland) Cohort and Biomarker Study and Repository for Idiopathic Inflammatory Myopathies $(n=410)$ prospectively collects clinical and laboratory data and samples on all children recruited to the study, using standardised protocols. 56 patients in the cohort were treated with cyclophosphamide between 20002011. Eight patients were excluded due to incomplete data or short follow up. The remaining 48 had a diagnosis of definite JDM, probable JDM or JDM overlap (Bohan and Peter criteria), with a minimum of 12 months follow up after the first dose of the cyclophosphamide. Demographic data, core set measures of disease activity, skin data,

'Rheumatology, Great Ormond Street, London, UK

Full list of author information is available at the end of the article laboratory measures, treatment data were analysed at baseline, 6, 12, 18, 24 months and last follow up.

\section{Results}

Indications for starting the cyclophosphamide were ulcerative or severe skin disease, profound muscle weakness, lung disease, gastro-intestinal vasculopathy or refractory disease. All patients starting with muscle weakness $(\mathrm{n}=44)$ significantly improved at 12 months, and the gains were maintained at follow up. Physician VAS was available at baseline for 32 patients and these all improved by 12 and 24 months, and for 31 remained stable at follow up. At last follow up, 26/46 (56\%) had no rash, 32/46 (69\%) had normal nailfolds, 37/45 (82\%) had no Gottron's, and calcinosis has resolved in 9/14 (64\%). The steroid dose was decreased by $65.8 \%$ at 6 months, and the majority of patients were off steroids or on very low doses at 24 months. Patients receiving cyclophosphamide had a significant decrease in steroid dose by 6 months, with most of the patients coming off steroids between 18 and 24 months.

\section{Conclusion}

These data suggest that cyclophosphamide provides clinical benefit in JDM patients with severe or refractory disease, improving both muscle and skin domains.

\section{Disclosure of interest}

None declared. 
Cite this article as: Moraitis et al:: PReS-FINAL-2130-A: Effectiveness of intravenous cyclophosphamide in severe or refractory juvenile dermatomyositis - a national cohort study UK and Ireland. Pediatric Rheumatology 2013 11(Suppl 2):P143.

Submit your next manuscript to BioMed Central and take full advantage of:

- Convenient online submission

- Thorough peer review

- No space constraints or color figure charges

- Immediate publication on acceptance

- Inclusion in PubMed, CAS, Scopus and Google Scholar

- Research which is freely available for redistribution

Submit your manuscript at www.biomedcentral.com/submit
C Biomed Central 